\title{
Energy Consumption Evaluation in Dark House Aviaries, With and Without Thermal Insulation: A Case Study in the Western Region of the State of Paraná
}

\author{
Ricardo Paganin ${ }^{1,2}$, Jair Antonio Cruz Siqueira ${ }^{1}$, Janaína Bedin ${ }^{1}$, Carlos Eduardo Camargo Nogueira ${ }^{1}$, \\ Carlos Roberto Moreira ${ }^{3}$, Samuel Nelson Melegari de Souza ${ }^{1}$, Flávia Strassburger ${ }^{4}$, Alex Strassburger ${ }^{4}$, \\ Mariane Motta de Campos $\mathrm{Cuchi}^{4} \&$ Mario Elias Carvalho do Nascimento ${ }^{1}$ \\ ${ }^{1}$ Post-Graduation in Energy Engineering in Agriculture, Western Paraná State University, Cascavel, Paraná, \\ Brazil \\ ${ }^{2}$ Graduation in Civil Engineering, Assis Gurgacz Foundation University, Cascavel, Paraná, Brazil \\ ${ }^{3}$ Graduation in Agronomy Engineering, Assis Gurgacz Foundation University, Cascavel, Paraná, Brazil \\ ${ }^{4}$ Post-Graduation in Bioenergy, Western Paraná State University, Toledo, Paraná, Brazil \\ Correspondence: Ricardo Paganin, Post-graduation in Energy Engineering in Agriculture, Western Paraná State \\ University, Cascavel, Paraná 85819-110, Brazil. Tel: 55-(45)-99139-7542. E-mail: engpaganin@gmail.com
}

Received: February 10, $2020 \quad$ Accepted: March 24, $2020 \quad$ Online Published: April 15, 2020

doi:10.5539/jas.v12n5p101 URL: https://doi.org/10.5539/jas.v12n5p101

\begin{abstract}
Broilers production suffered, due to major investments in technology and genetic development in recent decades, to adapt to the conditions and requirements of the national and world market. Studies on the production systems of reraring show the importance of the economy in the sector, which is one of the most competitive in the agribusiness sector. The present work aimed at studying two dark house aviaries construction, with and without thermal insulation, to evaluate the variations in temperature, gas consumption, and effect of the insulation. Both facilities were checked for temperature variation, using J-type thermocouple sensors and recording in datalogger; LPG consumption, and the production performance considering mortality of birds, feed consumption, water intake, and weight gain. It was concluded that the Dark House with Thermal Insulation (DHTI) aviary showed better broiler birds performance indexes, lower mortality, and greater weight gain. But when it comes to performance in the face of temperature conditions, the Conventional Dark House (CDH) aviary showed values better suited to the production, as noted in the bibliographic references.
\end{abstract}

Keywords: energy consumption evaluation, dark house aviaries, thermal insulation

\section{Introduction}

Technological advances in Brazilian poultry industry in recent decades have been decisive for the segment to consolidate itself as one of the most competitive in the agro-industrial sector. Brazilian poultry industry ranked first in the world in exports and second in broiler production - a placement that guarantees about $9 \%$ of the country's exports, generating more than two million direct and indirect jobs according to the Brazilian Animal Protein Association-ABPA (2019), in 2018. In 2018 alone, Brazil exported a total volume of 4,101 million tons of chicken meat, amounting to US \$ 6.571 billion. The state of Paraná produced about 4.56 million tons of chicken meat, representing around $35.47 \%$ of chicken meat in the country. The total national production of chicken meat reached 12.86 million tons in 2018.

Genetic improvements; investments in technology; and care for health, nutrition, environment, and better quality of management justify this lead and potential. The environment plays an important role on production, as an inadequate environment leads to a drop in production and meat quality, consequently incurres losses to the producer (Souza, 2005).

With advancement of time, the environment and the equipment for the poultry production undergo changes, and the same is true for suitable aviaries for the birds, especially in terms of thermal control and easy handling. Thus, aviaries have been adapting and modernizing with the use of equipment and systems that provide better automation and production control, such as the use of exhausters, heating systems, evaporative panels and air 
and temperature control systems. Investments in technology and improvement of production systems can be identified in the Dark House model, with artificial control of thermal parameters during the production period, which allows greater density and, consequently, greater production per batch.

Nonetheless, there is a concern in terms of the automation of this confinement model, which uses equipment for handling and environmental comfort, demanding greater energy consumption in production. According to the United States Department of Agriculture-USDA (2019), in 2020, the Brazilian scenario of production of broilers is expected to grow about $2.5 \%$. This expectation of production for Brazilian poultry industry implies an increase in demand for electricity for production.

The challenge lies in building model capable of providing better environmental conditions in view of the handling and climatic characteristics that meet the parameters of sustainability, conservation, and rationalization of energy, seeking to contribute to a reduction in consumption, considering economy and effective control of environment.

In this context, the general objective of this study was to assess gas consumption and production performance in terms of mortality and culling; water and feed consumption; and weight gain, in two Dark House aviaries - a conventional one and one with thermal insulation on energy economy.

\section{Method}

The present research was carried out on two commercial broiler aviaries located in the municipality of Palotina, in the extreme west of the state of Paraná. The geographical coordinates of the location are: Latitude $24^{\circ} 16^{\prime} 54^{\prime \prime}$ South, Longitude: $53^{\circ} 50^{\prime} 25^{\prime \prime}$ West, and 341 meters of altitude. The region's climate, according to Köppen's (1948) classification, is called Subtropical (Cfa), without well-defined dry seasons. Gardim (2008) reports that the relative humidity of the air is between 70 and $81 \%$, with average temperatures of $21{ }^{\circ} \mathrm{C}$, and average annual precipitation of 1400 to $1500 \mathrm{~mm}$.

The broilers sheds used in this research belong to a complex of six aviaries, commercial poultry properties integrated to an Agroindustrial Cooperative. The studied aviaries are positioned side by side with a distance of 20 meters between them, oriented in the North-South direction.

\subsection{Conventional Dark House (CDH) Aviary}

The Conventional Dark House (CDH) aviary has dimensions of 15 meters wide, 150 meters long, totaling 2.250 $\mathrm{m}^{2}$ and ceiling height of 2.60 meters. The north and south faces are sealed in aluminum sheets and the east and west faces with a black polyethylene curtain inside and reflective on the outside, with the base of the building delimited by a $0.50 \mathrm{~m}$ high and 0.28 thick wall of concrete blocks. The shed has black polyethylene lining and the aviary is covered with $0.40 \mathrm{~mm}$ thick aluminum roof (Figure 1).

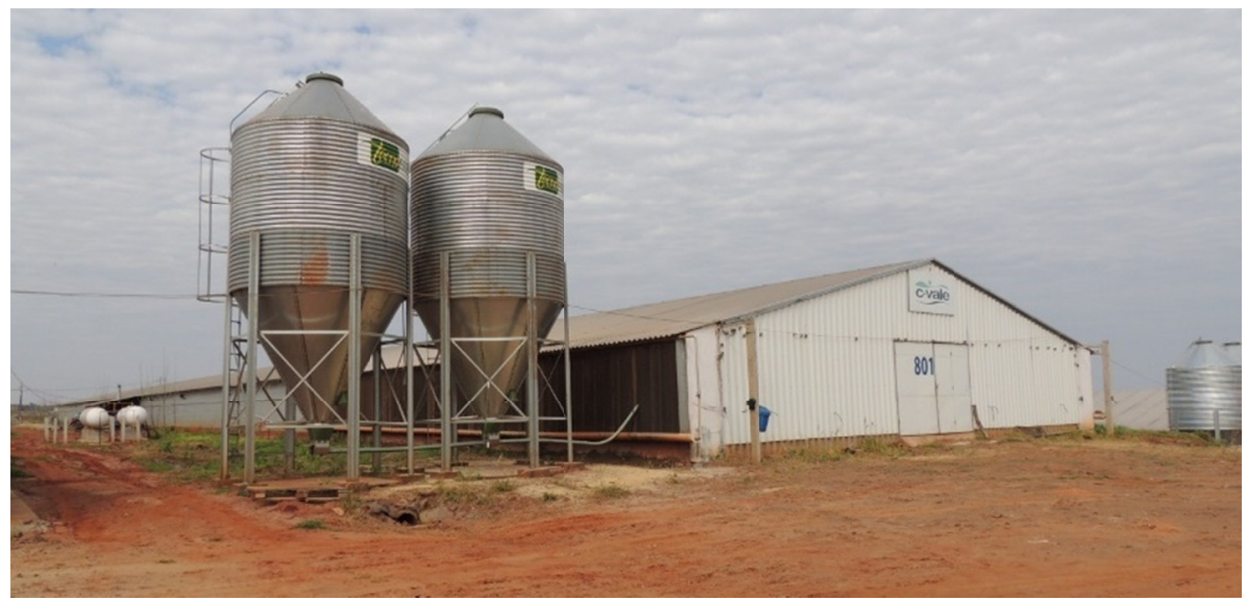

Figure 1. Conventional Dark House $(\mathrm{CDH})$ aviary—north face

At the north end of the aviary, on the east and west sides, are located the evaporative panel or pad cooling systems, with a length of 20 meters and a height of 1.80 meters. At the opposite end, there are cone-shaped exhausters, with 1.15 meters in diameter, six on the south side and three on each of the east and west faces, totaling 12 exhausters. 
For heating the aviary, the Convective Radiant Tube (CRT) system is used, an equipment developed to adjust to the aviary management techniques, where the system works through air flow (convection) and radiation (direct heat) within these environments. According to Gás Sistem (2014), the CRT generates, as a consequence, the better use of heat and adaptation to equipment, observing savings in the consumption of Liquefied Petroleum Gas (LPG).

The CRT heating system uses LPG as energy, where there is no need for electric motors. Associated with the $\mathrm{CRT}$, there is an extractor that promotes an auxiliary distribution of heat through the convection process. This extractor uses electricity for operation, and its activation is auxiliary to the CRT system, used only when there is a drop in the temperature of the aviary or in the minimum ventilation system. Each aviary under experiment has six heating devices (CRT).

\subsection{Dark House with Thermal Insulation (DHTI) Aviary}

The Dark House with Thermal Insulation (DHTI) aviary is 16 meters wide and 150 meters long, totaling an area of $2.400 \mathrm{~m}^{2}$ and ceiling height of 2.60 meters. All sides are sealed through a system of double aluminum sheets with an insulating material core, the aluminum sheets are $0.40 \mathrm{~mm}$ thick, and those exposed to the outside are painted in white and those located inside the aviary are covered with expandable polystyrene (EPS), the filling of the core of this system is through the use of extruded polystyrene (XPS), with a thickness of $30 \mathrm{~mm}$, applied between the sealing plates. Thus, the walls have a total thickness of $30.8 \mathrm{~mm}$ (Figure 2). The doors also have insulation with aluminum finishes, constituting a system similar to that used in cold rooms.

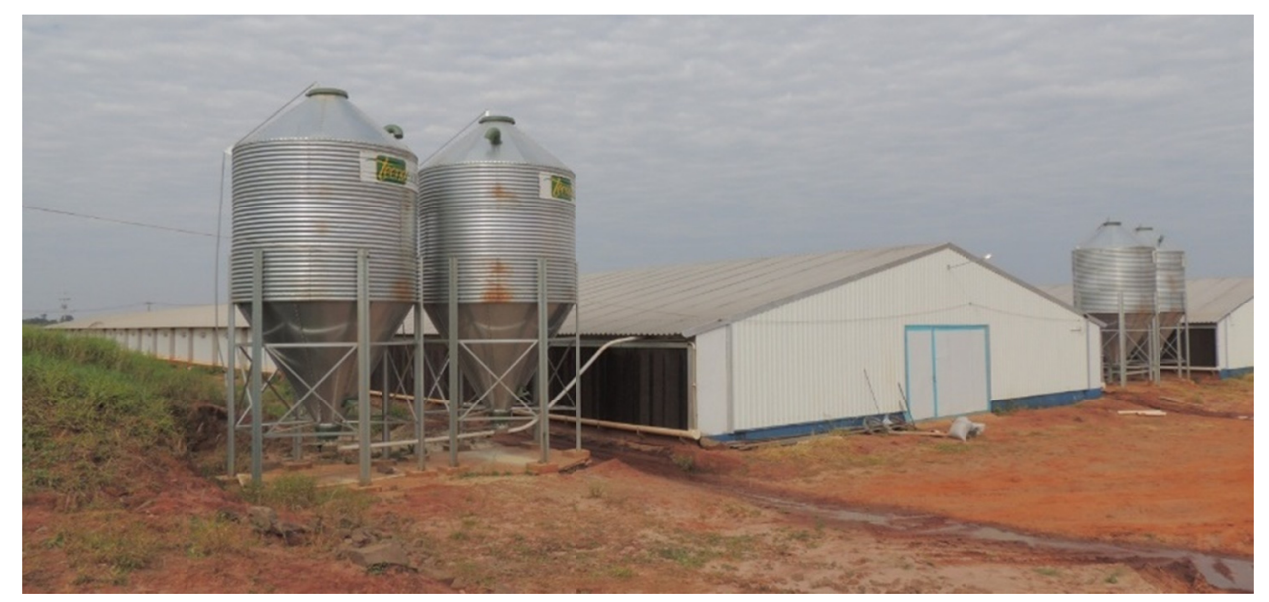

Figure 2. Dark House with Thermal Insulation (DHTI) aviary—north face

At the base of the shed is a short wall $0.50 \mathrm{~m}$ high and 0.54 thick, in masonry of concrete blocks. The shed has yellow polyethylene lining and the aviary is covered with $0.40 \mathrm{~mm}$ thick aluminum roof and thermal insulation with $30 \mathrm{~mm}$ XPS plates.

At the north end of the aviary, on the east and west sides, are located the evaporative panel systems, with a length of 20 meters and height of 1.80 meters. At the opposite end, there are cone-shaped exhauts, 1.15 meters in diameter, six on each of the east and west faces, totaling 12 exhausters.

The heating system of this aviary is also through LPG gas via Convective Radiant Tube, an equipment manufactured in stainless steel with temperature control that uses air flow (convection) and radiation (direct heat). The CRTs are arranged along the length of the aviary. In the DHTI aviary, six pieces of equipment are also installed along the longitudinal axis.

Both evaluated aviaries are supplied with Liquefied Petroleum Gas (LPG) stored in two horizontal P-1000 tanks, where each tank has a storage capacity of $1.000 \mathrm{~kg}$, totaling $2.000 \mathrm{~kg}$ of LPG. The distribution of gas to the aviaries is carried out through a central or primary network, connected to secondary connection points for internal distribution throughout the aviary. 


\subsection{Measuring Instruments and Systems}

The evaluation of the energy consumption of the two aviaries was carried out based on their thermal control system, both inside and outside, during the period of production of the birds, where the following data were verified: air temperature and gas consumption.

\subsubsection{Air Temperature}

The air temperature was checked inside and outside the aviaries. In the external area, a sensor was installed, equidistant between the aviaries, for the continuous measurement of air temperature throughout the experiment. In the internal area, in order to characterize the level of thermal comfort, the air temperature was verified through the installation of temperature sensors. To check the temperature, Switerm's Type J Thermocouples SMTJ $8 \mathrm{~mm}$ were used, consisting of two distinct metallic conductors, according to the specifications in Table 1. Three internal sensors were used in each aviary to determine the average temperature, one being 6 meters long and two 12 meters long, due to the distance from the measurement point to the temperature recorder.

Table 1. Technical specifications of Switerm's Type J Thermocouple

\begin{tabular}{|c|c|}
\hline Code & SMTJ 8 mm \\
\hline Composition & Iron (+)/Copper-Nickel (-) \\
\hline \multirow[t]{5}{*}{ Description } & Brass Tip \\
\hline & 1/4 Thread Adapter (BSP) \\
\hline & $\varnothing 19 \mathrm{~mm}$ Aluminum bayonet \\
\hline & $2 \times 24$ metallic braid cable \\
\hline & Pin or fork connection terminals \\
\hline Aplication Range & -40 to $750^{\circ} \mathrm{C}$ \\
\hline Polarity Identification & General industries up to $750^{\circ} \mathrm{C}$. \\
\hline Electromotive Force produced & 0 to $42.922 \mathrm{mV}$ \\
\hline Average thermoelectric power & $5.65 \mathrm{mV} / 100^{\circ} \mathrm{C}$ \\
\hline Length & $2 \mathrm{~m} ; 3 \mathrm{~m} ; 4 \mathrm{~m} ; 5 \mathrm{~m} ; 6 \mathrm{~m} ; 12 \mathrm{~m}$ \\
\hline Characteristics & $\begin{array}{l}\text { These thermocouples are suitable for use in vacuum or in oxidizing, } \\
\text { reducing, and inert atmospheres. }\end{array}$ \\
\hline
\end{tabular}

To store data and record air temperature measurements, a MasterLogger A 202 Datalogger, from the manufacturer Contemp, was used, with 8 channels and technical characteristics described in Table 2.

Table 2. Technical specifications of Contemp's MasterLogger A 202 datalogger

\begin{tabular}{ll}
\hline Supply & 85 to $265 \mathrm{Vac}, 47$ to $63 \mathrm{~Hz}$, or 85 to $265 \mathrm{Vdc}$ \\
Internal memory & $2 \mathrm{MB}$ \\
Weight & $230 \mathrm{~g}$ \\
Operating Temperature & $-10{ }^{\circ} \mathrm{C}$ to $55^{\circ} \mathrm{C}$ \\
Protection Index & $\mathrm{IP} 40$ \\
Analog Inputs & 8 \\
Digital Inputs/Outputs & 8 \\
Input impedance of analog channels & Thermocouples B, S, R, T, N, E, K, J; PT100; 0 to $60 \mathrm{mV}, \pm 60 \mathrm{mV} ;$ \\
& 0 to $20 \mathrm{~mA}$ or 4 to $20 \mathrm{~mA} ; 0$ to $5 \mathrm{~V}, 1$ to $5 \mathrm{~V}, 0$ to $10 \mathrm{~V}, \pm 5 \mathrm{~V}, \pm 10 \mathrm{~V}$ \\
Digital Inputs & Maximum input voltage: $30 \mathrm{Vdc}$ \\
& Input current at $30 \mathrm{Vdc}$ (typical): $3 \mathrm{~mA}$ \\
Digital Outputs & Maximum output voltage: $30 \mathrm{Vdc}$; Maximum output current: $200 \mathrm{~mA}$ \\
\hline
\end{tabular}

The datalogger was used to collect the voltage variation in the sensors, and the values to compare temperature difference were recorded at every 5 minutes.

\subsubsection{LPG Consumption}

For the evaluation of gas consumption, volumetric gas meters were installed in each of the evaluated aviaries, located in the secondary distribution network. The equipment used was LAO's G10 gas meter. The operating 
principle consists of channels between four chambers that move the diaphragms that coordinate the loading and unloading of the system, activating the rotary valve that moves the integration system.

The equipment totalizer has an is 8-digit cyclometric register, with an optical reading marking. The technical data of the equipment is shown in Table 3.

Table 3. Technical data of LAO's G10 gas meter

\begin{tabular}{llll}
\hline \multirow{2}{*}{ GAS TYPE $\left(\mathrm{m}^{3} / \mathrm{h}\right)$} & \multicolumn{3}{c}{ TECHNICAL DATA } \\
\cline { 2 - 4 } & MAXIMUM FLOW $\left(\mathrm{m}^{3} / \mathrm{h}\right)$ & MINIMUM FLOW $\left(\mathrm{m}^{3} / \mathrm{h}\right)$ & CYCLIC VOLUME $\left(\mathrm{dm}^{3}\right)$ \\
\hline AIR & 16 & 0.10 & 4 \\
NATURAL GAS & 20 & 0.10 & 4 \\
LPG & 13 & 0.10 & 4 \\
\hline
\end{tabular}

The meters were installed outside the aviaries, connected to the secondary network that distributes the gas to the heaters inside the aviaries.

\subsubsection{Broiler Birds Performance}

To determine the broiler birds' performance, the most common zootechnical indexes, recorded daily, were used. The verified indexes were:

a) Mortality (M) and Culling (C): obtained by surveying and counting of the birds in loco;

b) Feed Consumption (FC): amount of feed consumed during the production period, obtained through weighing;

c) Water Consumption (WC): amount of water ingested during the production period;

d) Weight Gain (WG): the weighing was done at intervals of 7 days.

\subsection{Data Analysis}

For data analysis, the project was divided into two construction systems, considering the data obtained in the Conventional Dark House (CDH) aviary and in the Dark House with Thermal Insulation (DHTI) aviary, with two production periods being considered for each of the models, the initial one (broilers' initial growth period, with a period of 0 to 7 days of age, in an expandable area internal to the shed called a chicken coop, corresponding to the need for heating the birds. In this phase, it was possible to verify the gas consumption for heating) and the final one (period characterized by the growth of birds, comprising 22 to 29 days, period in which the consumption of electricity was evaluated). The results obtained were presented in the form of tables and graphs, enabling the comparison between the two systems and an analysis of the variables obtained in the birds' confinement time and their breeding phase.

\section{Results and Discussion}

\subsection{Temperature}

The average temperature values $\left({ }^{\circ} \mathrm{C}\right)$ verified through the sensors and registered in the datalogger are shown in Table 4. It is observed that the highest external temperature recorded was $38.1^{\circ} \mathrm{C}$, on the first day of confinement $(08 / 01)$, and the highest internal temperatures recorded were on the second day $(09 / 01)$, where in the CDH aviary registered $31.4{ }^{\circ} \mathrm{C}$, and the DHTI aviary $35.1^{\circ} \mathrm{C}$. 
Table 4. External, $\mathrm{CDH}$ and DHTI temperature in ${ }^{\circ} \mathrm{C}$

\begin{tabular}{|c|c|c|c|c|c|}
\hline \multicolumn{3}{|l|}{ TIME } & \multicolumn{3}{|c|}{ TEMPERATURE $\left({ }^{\circ} \mathrm{C}\right)$} \\
\hline MONTH & DAY & WEEK & EXTERNAL & CDH AVIARY & DHTI AVIARY \\
\hline \multirow{24}{*}{ 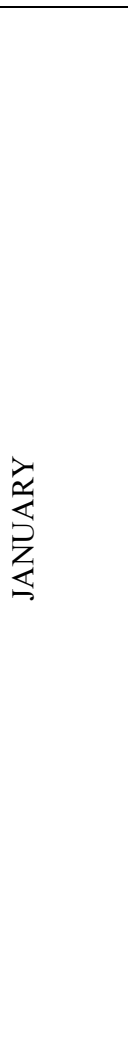 } & 08 & \multirow{7}{*}{ 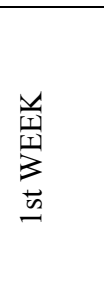 } & 38.1 & 30.9 & 34.2 \\
\hline & 09 & & 37.7 & 31.4 & 35.1 \\
\hline & 10 & & 37.2 & 30.7 & 34.8 \\
\hline & 11 & & 35.8 & 29.5 & 34.3 \\
\hline & 12 & & 33.3 & 29.9 & 33.5 \\
\hline & 13 & & 29.8 & 28.7 & 32.9 \\
\hline & 14 & & 29.4 & 29.2 & 32.5 \\
\hline & 15 & \multirow{7}{*}{ 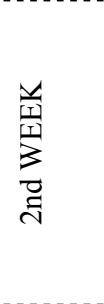 } & 33.8 & 29.5 & 32.1 \\
\hline & 16 & & 34.9 & 27.9 & 32.7 \\
\hline & 17 & & 34.4 & 27.5 & 31.6 \\
\hline & 18 & & 35.1 & 27.6 & 31.7 \\
\hline & 19 & & 36.3 & 26.3 & 28.9 \\
\hline & 20 & & 34.5 & 25.4 & 30.1 \\
\hline & 21 & & 33.6 & 26.1 & 30.8 \\
\hline & 22 & \multirow{7}{*}{ 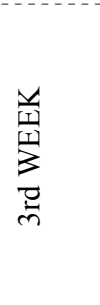 } & 31.5 & 24.8 & 30.3 \\
\hline & 23 & & 27.2 & 24.5 & 29.5 \\
\hline & 24 & & 27.9 & 25.1 & 29.8 \\
\hline & 25 & & 31.7 & 23.8 & 28.5 \\
\hline & 26 & & 32.7 & 23.6 & 27.4 \\
\hline & 27 & & 32.9 & 24.8 & 28.2 \\
\hline & 28 & & 33.4 & 24.2 & 28.6 \\
\hline & 29 & \multirow{7}{*}{$\begin{array}{l}\frac{v}{1} \\
\frac{1}{y} \\
3 \\
\frac{I}{f}\end{array}$} & 34.9 & 23.4 & 27.9 \\
\hline & 30 & & 32.5 & 23.8 & 27.1 \\
\hline & 31 & & 28.6 & 22.7 & 27 \\
\hline \multirow{4}{*}{ 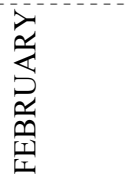 } & 1 & & 31.7 & 22.9 & 26.5 \\
\hline & 2 & & 35.3 & 23.2 & 24.3 \\
\hline & 3 & & 34.6 & 22.6 & 25.7 \\
\hline & 4 & & 28.8 & 22.4 & 24.3 \\
\hline
\end{tabular}

In the graphical representation of Figure 3, it can be seen that the DHTI aviary temperature was higher than the $\mathrm{CDH}$ aviary temperature. Regarding the external temperature, the $\mathrm{CDH}$ aviary presented an internal temperature always lower than the external one, and on January 14 , there was the smallest variation of $0.2{ }^{\circ} \mathrm{C}$. The DHTI aviary presented greater temperature variations, and in the period from 12/01 to $14 / 01$, corresponding to the 1 st week, and in the 3rd week (23/01 and 24/01) internal temperatures are higher than the external ones. 


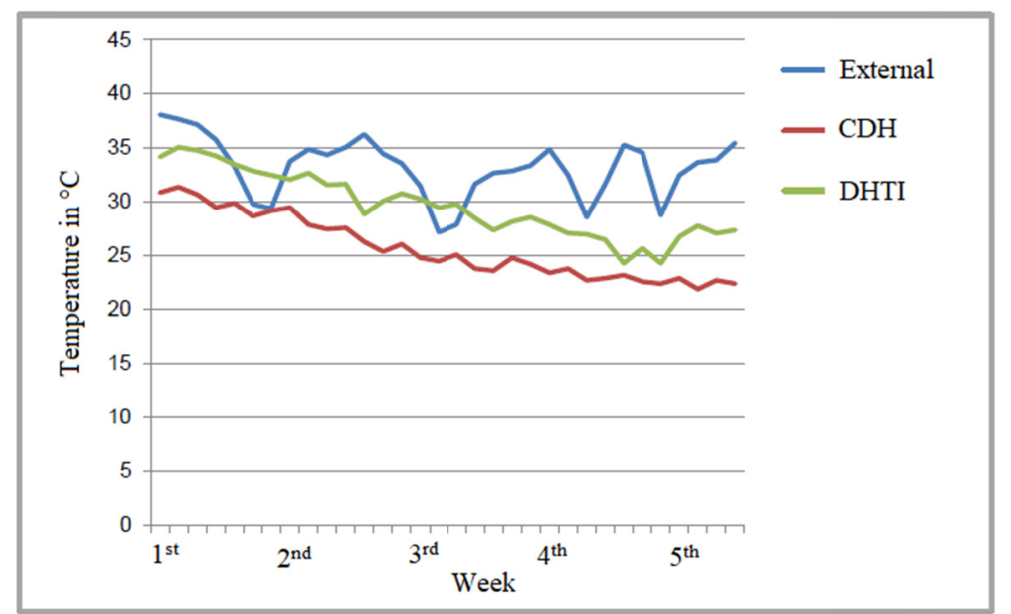

Figure 3. Comparison of external and internal temperatures of $\mathrm{CDH}$ and DHTI aviaries

It can be concluded that the average temperatures of the Conventional Dark House (CDH) aviary were within the comfortable temperature range as highlighted by Yahav (2002), and Macari and Furlan (2001). It is observed that the internal temperature in the first week remained in the range of 33 to $35^{\circ} \mathrm{C}$ and, according to the growth of the birds, the temperature decreased reaching the range of 25 to $21{ }^{\circ} \mathrm{C}$, as recommended by Macari and Furlan (2001). The Dark House with Thermal Insulation (DHTI) aviary presented values in the first two weeks within the comfortable temperature range for birds and in the following weeks above desirable values.

In general, the DHTI aviary temperature was higher than the CDH aviary temperature. Regarding the external temperature, the $\mathrm{CDH}$ aviary presented an internal temperature always lower than the external one and the DHTI aviary presented greater temperature variations, with periods of internal temperatures higher than the external ones-parameters that are not desirable and outside the standards recommended for the development of the birds.

In view of the temperature analysis, it is assumed that the best performance of the Conventional Dark House $(\mathrm{CDH})$ aviary is due to the construction differences, in addition to the arrangement of the exhausters responsible for the air circulation inside the aviary, which are located on the side and in the back of the aviary, thus generating a better flow and consequent heat removal. The Dark House with Thermal Insulation (DHTI) aviary has the exhausters located on the sides of the aviary, in the east and west directions, which provides less air flow and circulation.

\subsection{Gas Consumption}

Table 5 shows the values of gas consumption in the period evaluated. According to the daily record, it is observed that the artificial heating was provided only in the first five days of the rearing of chicks.

Table 5. Values of gas consumption of the evaluated aviaries

\begin{tabular}{llllll}
\hline \multirow{2}{*}{ DAY } & \multicolumn{3}{c}{ Conventional Dark House $(\mathrm{CDH})$} & & Dark House with Thermal Insulation (DHTI) \\
\cline { 2 - 3 } \cline { 5 - 6 } & RECORDED VALUE & CONSUMPTION $\left(\mathrm{m}^{3}\right)$ & & RECORDED VALUE & CONSUMPTION $\left(\mathrm{m}^{3}\right)$ \\
\hline & 1973 & - & 187 & 1977 & - \\
2 & 2080 & 98 & 2063 & 97 \\
3 & 2178 & 93 & 2142 & 79 \\
4 & 2271 & 87 & 2217 & 75 \\
5 & 2358 & 81 & 288 & 71 \\
\hdashline TOTAL $\left(\mathrm{m}^{3}\right)$ & 2439 & 466 & & 408 \\
\hline
\end{tabular}

According to data in Table 5, it is possible to observe that the $\mathrm{CDH}$ aviary consumed a total of $466 \mathrm{~m}^{3}$ of gas, while DHTI totaled $408 \mathrm{~m}^{3}$ of gas. When comparing the two aviaries, it is observed that a difference of $12.45 \%$ in gas consumption. This factor was identified by the greater ease of heat loss that the $\mathrm{CDH}$ aviary has, in view 
of the less insulation of the sealing materials, and the greater propensity to air flows due to the less tightness of the system, promoting the removal of heat.

\subsection{Broiler Birds Performance}

The mortality $(\mathrm{M})$ and culling $(\mathrm{C})$ data of the birds confined in the two evaluated aviaries, under the effect of the two distinct construction systems, Conventional Dark House (CDH) aviary and in the Dark House with Thermal Insulation (DHTI) aviary, at the end of the evaluation period (four weeks), are shown in Table 6.

Table 6. Values of mortality and culling of birds in aviaries

\begin{tabular}{|c|c|c|c|c|c|c|c|c|c|c|}
\hline \multirow{3}{*}{ WEEK } & \multicolumn{5}{|c|}{ Conventional Dark House (CDH) } & \multicolumn{5}{|c|}{ Dark House with Thermal Insulation (DHTI) } \\
\hline & \multicolumn{2}{|c|}{ TOTAL WEEKLY } & \multicolumn{3}{|c|}{ TOTAL ACCUMULATED } & \multicolumn{2}{|c|}{ TOTAL WEEKLY } & \multicolumn{3}{|c|}{ TOTAL ACCUMULATED } \\
\hline & M & $\mathrm{C}$ & $\mathrm{M}$ & $\mathrm{C}$ & $\mathrm{M}+\mathrm{C}$ & M & $\mathrm{C}$ & $\mathrm{M}$ & $\mathrm{C}$ & $\mathrm{M}+\mathrm{C}$ \\
\hline $1^{\circ}$ & 184 & 130 & 184 & 130 & 314 & 98 & 71 & 98 & 71 & 169 \\
\hline $2^{\circ}$ & 70 & 18 & 254 & 148 & 402 & 52 & 6 & 150 & 77 & 227 \\
\hline $3^{\circ}$ & 45 & 11 & 299 & 159 & 458 & 43 & 2 & 193 & 79 & 272 \\
\hline $4^{\circ}$ & 45 & 18 & 344 & 177 & 521 & 36 & 16 & 229 & 95 & 324 \\
\hline
\end{tabular}

Note. Dead birds (M), birds Culled (C).

It can be observed that in the Conventional Dark House (CDH) aviary there was a higher mortality rate of birds, totaling 344 birds with a standard deviation of 66, while in the Dark House with Thermal Insulation (DHTI) aviary, the total number of dead birds was 299 , with a standard deviation of 27 , at the end of the fourth week. The birds culled totaled 177 in the CDH aviary and 95 birds in the DHTI on, with a standard deviation of 57 and 32 , respectively.

Through the analysis of the data of the dead birds in both aviaries and of the temperature data in the first week, it is found that the temperatures in DHTI are more suitable for the birds, providing a smaller number of dead birds, which was 98, while in $\mathrm{CDH}$ it represented 184 dead birds. Thus, it is concluded that in the initial phase, that is, the initial growth period of broilers, from 0 to 7 days old, the DHTI aviary presents a better performance of broiler birds production, with a smaller number of dead birds.

According to the data analysis, it can be verified that in the CDH aviary there was a $33.43 \%$ higher mortality than in the DHTI one, while the percentage of birds culled in the same aviary was $46.33 \%$ higher than in the thermally insulated aviary.

Regarding the amount of feed consumed during the evaluated period, it can be observed that in the Dark House with Thermal Insulation (DHTI) aviary there was a higher feed consumption than in the CDH aviary, with $94.320 \mathrm{~kg}$ and $91.958 \mathrm{~kg}$ respectively, a difference of $2.5 \%$.

According to the mortality and culling data, the DHTI aviary represented lower total quantities in the evaluated periods, that is, a greater number of growing birds. In view of the above, it is concluded that feed consumption was higher in the aviary, as a result of a greater number of birds in production, than in the $\mathrm{CDH}$ aviary.

The amount of water consumed during the production period is shown in Table 7. According to data analysis, it is observed that in the CDH aviary the water consumption was 121.260 liters and in the DHTI the total consumption was 126.597 liters, thus, it can be concluded that the DHTI aviary presented, in addition to higher feed consumption, a $4.22 \%$ higher percentage of water consumption. 
Table 7. Water Consumption (WC) values in CDH and DHTI aviaries

\begin{tabular}{|c|c|c|c|c|}
\hline \multirow{2}{*}{ DAY } & \multicolumn{2}{|c|}{ Conventional Dark house (CDH) } & \multicolumn{2}{|c|}{ Dark House with Thermal Insulation (DHTI) } \\
\hline & WATER READING & CONSUMPTION (L) & WATER READING & CONSUMPTION (L) \\
\hline 0 & 1980 & 770 & 8650 & 1030 \\
\hline 1 & 2057 & 1520 & 8753 & 1530 \\
\hline 2 & 2209 & 2020 & 8906 & 2060 \\
\hline 3 & 2411 & 2310 & 9112 & 2330 \\
\hline 4 & 2642 & 1960 & 9345 & 2660 \\
\hline 5 & 2838 & 2560 & 9611 & 3680 \\
\hline 6 & 3094 & 2800 & 9979 & 3040 \\
\hline 7 & 3200 & 3100 & 283 & 3180 \\
\hline 8 & 3677 & 3640 & 601 & 3860 \\
\hline 9 & 4041 & 3500 & 987 & 3900 \\
\hline 10 & 4391 & 4300 & 1351 & 4000 \\
\hline 11 & 4821 & 4120 & 1795 & 4340 \\
\hline 12 & 5233 & 4760 & 2229 & 4340 \\
\hline 13 & 5709 & 5170 & 2663 & 5530 \\
\hline 14 & 6226 & 5720 & 3216 & 5780 \\
\hline 15 & 6798 & 5520 & 3794 & 5930 \\
\hline 16 & 7350 & 6300 & 4387 & 6750 \\
\hline 17 & 7980 & 6650 & 5062 & 7050 \\
\hline 18 & 8645 & 6660 & 5767 & 7030 \\
\hline 19 & 9311 & 7060 & 6470 & 6950 \\
\hline 20 & 17 & 7990 & 7165 & 7867 \\
\hline 21 & 816 & 7500 & 7915 & 7630 \\
\hline 22 & 1566 & 8420 & 8687 & 8580 \\
\hline 23 & 2408 & 8500 & 9532 & 8930 \\
\hline 24 & 3266 & 8410 & 419 & 8620 \\
\hline TOTAL & & 121260 & & 126597 \\
\hline
\end{tabular}

As the DHTI aviary had higher temperatures in the evaluated period, and a greater number of birds in the growing period, due to lower mortality and culling, it is concluded that the higher water consumption is influenced by these two variables.

Regarding the monitoring of the birds' weight gain, Table 8 shows the values obtained by weekly measurements.

Table 8. Weight gain (GP) values in CDH and DHTI aviaries

\begin{tabular}{lll}
\hline DAYS & Conventional Dark house (CDC) & Dark House with Thermal Insulation (DHTI) \\
\hline & - & - \\
01 & - & 214 \\
07 & 209 & 499 \\
21 & 518 & 990 \\
28 & 960 & 1620 \\
\hline
\end{tabular}

Considering the difference in final weight and the initial weight of the birds, performed every seven days, it can be seen that in the Dark House with Thermal Insulation (DHTI) aviary the average weight gain was 20 grams more than in the $\mathrm{CDH}$ aviary, at the end of 28 days of confinement.

\subsection{Comparison of Results}

In Table 9, the two construction systems are compared, Conventional Dark House (CDH) and Dark House with Thermal Insulation (DHTI), allowing a general comparison of variables and broiler birds performance, verified and discussed in the present work. 
Table 9. Comparison of variables and broiler birds performance of CDH and DHTI aviaries

\begin{tabular}{|c|c|c|}
\hline CONSUMPTION/VARIABLE & CONVENTIONAL DARK HOUSE (CDH) & DARK HOUSE WITH THERMAL INSULATION (DHTI) \\
\hline Temperature & 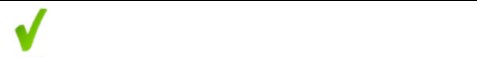 & $X$ \\
\hline GAS & $\mathcal{X}$ & $\sqrt{ }$ \\
\hline BROILER BIRDS PERFORMANCE & CONVENTIONAL DARK HOUSE (CDH) & DARK HOUSE WITH THERMAL INSULATION (DHTI) \\
\hline Mortality (M) & $X$ & 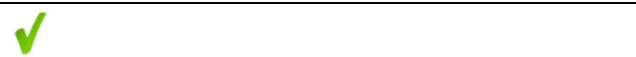 \\
\hline Culling (C) & $\boldsymbol{X}$ & $\sqrt{ }$ \\
\hline Feed consumption (FC) & $\sqrt{ }$ & $\boldsymbol{X}$ \\
\hline Water consumption (WC) & $\sqrt{ }$ & $\boldsymbol{X}$ \\
\hline Weight Gain (WG) & $\boldsymbol{X}$ & $\sqrt{ }$ \\
\hline
\end{tabular}

The aviary that uses the DHTI system presented better broiler birds performance indexes with less mortality and culling, and greater weight gain. However, when evaluated the performance against the temperature conditions, the $\mathrm{CDH}$ aviary presented values more adequate to the production, according to Naas et al. (2001), Macari and Furlan (2001), and Menegali (2009).

\section{Conclusion}

It can be concluded that the average temperatures of the Conventional Dark House (CDH) aviary were within the comfortable temperature range as recommended by Macari and Furlan (2001). The Dark House with Thermal Insulation (DHTI) aviary presented values in the first two weeks within the comfortable temperature range for birds and in the following weeks values were above those desirable.

In general, the DHTI aviary temperature was higher than the CDH aviary temperature. Regarding the external temperature, the $\mathrm{CDH}$ aviary presented an internal temperature always lower than the external one and the DHTI aviary presented greater temperature variations, with periods of internal temperatures higher than the external ones-parameters that are not desirable and outside the standards recommended for the development of the birds.

As for the consumption of gas for the heating of the aviaries, it was concluded that the $\mathrm{CDH}$ aviary had a higher consumption than the DHTI aviary, due to the heat losses because of the thermal insulation.

In the $\mathrm{CDH}$ aviary there was a higher mortality rate of birds compared to the same period in the DHTI aviary.

The amount of feed consumed during the period evaluated in the DHTI aviary was higher than that of the CDH one, a fact also observed in water consumption.

In the difference in the final weight and initial weight of the birds, performed every seven days, it can be seen that in the DHTI aviary the average weight gain was greater than in the CDH aviary.

Regarding the determination of the best broiler bird's production system, CDH or DHTI, of the variables evaluated, the DHTI aviary presented better broiler birds performance indexes with less mortality and culling, and greater weight gain. However, when evaluated the performance against the temperature conditions, the CDH aviary presented values more adequate to the production.

\section{Acknowledgements}

The authors would like to thank the support of the Assis Gurgacz Foundation University and the Post-Graduation Program in Energy Engineering in Agriculture at the Western Paraná State University, Cascavel campus.

\section{References}

ABPA (Associação Brasileira de Proteína Animal). (2019). Relatório Anual 2019. Associação Brasileira de Pretína Animal, Brazil. Retrieved December 20, 2019, from http://abpa-br.org/relatorios

Gardim, D. C. (2008). Guia de produtos 2008 (1st ed.). Cascavel: Coodetec.

Gas Sistem. (2014). Imagem. Retrieved December 15, 2019, from http://www.gas.eco.br

Köppen, W. (1948). Climatologia: con un estudio de los climas de la tierra (1st ed.). México: Fondo de Cultura Económica.

Macari, M., \& Furlan, R. (2001). In I. J. O. Silva (Ed.), Ambiência na produção de aves em clima tropical (pp. 31-87). Jaboticabal: SBEA. 
Menegali, I. (2009). Avaliação de diferentes sistemas de ventilação mínima sobre a qualidade do ar e o desempenho de frangos de corte. Universidade Federal de Viçosa, Viçosa, Brazil.

Naas, I. A., Sevegnani, K. B., Marcheto, F. G., Espelho, J. C. C., Menegassi, V., \& Silva, I. J. O. da. (2001). Avaliação térmica de telhas de composição de celulose e betumem, pintadas de branco, em modelos de aviários com escala reduzida. Engenharia Agricola, 21(2), 121-126.

Souza, P. (2005). Avicultura e clima quente: como administrar o bem-estar às aves? Avicultura Industrial, 96(4), 52-58. Retrieved December, 2019, from https://www.aviculturaindustrial.com.br/edicao

USDA (United States Department of Agriculture). (2019). Poultry and Products Annual. United States Department of Agriculture, USA. Retrieved January 15, 2020, from http://www.usdabrazil.org.br/pt-br/ reports/poultry-and-products-annual-report-2019.pdf

Yahav, S. (2002). Heat stress in broiler (pp. 28-37). Anais da AMEVEA, Equador.

\section{Copyrights}

Copyright for this article is retained by the author(s), with first publication rights granted to the journal.

This is an open-access article distributed under the terms and conditions of the Creative Commons Attribution license (http://creativecommons.org/licenses/by/4.0/). 